\title{
Retropharyngeal abscess: three unusual cases
}

\begin{abstract}
Introduction: Deep neck space abscess generally cure with medical treatment and needs hospitalization with parenteral antibiotic use. Retropharyngeal space is one of the deep neck spaces and abscess of this space is rarely encountered. Retropharyngeal abscess may cause mortality due to airway obstruction or extension to the danger space.
\end{abstract}

Cases: Three unusual adult male patients were evaluated with retropharyngeal abscess. The common condition for all of them was the existence of poor social status and comorbid diseases

Conclusion: Extended abscess may show spontaneous drainage and can cause respiratory arrest due to purulent aspiration. In adult patients underlying factors must be controlled and surgical intervention should be evaluated as a step of the treatment.

Keywords: retropharyngeal abscess, spontaneous drainage, airway obstruction, diabetes mellitus, aspiration pneumonia, epidural abscess, jugular venous thrombosis
Volume 5 Issue 3 - 2016

Osman Halit Çam, ${ }^{2}$ Numan Kökten,' Adem

Kilıçaslan, ${ }^{3}$ Fatih Mehmet Hanege, ${ }^{4}$ Lokman Uzun,' Muhammet Tekin'

'Department of ENT Goztepe Training and Research Hospital Istanbul Medeniyet University, Turkey

${ }^{2}$ Department of ENT, Turkey

${ }^{3}$ Department of ENT, Mu? State Hospital,Turkey

4Department of ENT Giresun Private Ada Hospital,Turkey

Correspondence: Osman Halit Cam, Unalan Mahallesi Sarnıc Sokak, New City Istanbul No: 3/A2/19, Uskudar-ISTANBUL, Turkey,Tel +90 505 70I 84 70, Email Osman.cam@gmail.com

Received: September 28, 2016 | Published: December 30, 2016

\section{Introduction}

Retropharyngeal abscess is an emergency situation that originates from one of the deep neck spaces and may result with death by airway obstruction. Local trauma to the phayrnx (fishbone laceraitons), medical procedures (direct laringoscopy, entubation) and dentigious infectious are blamed in the ethiology. Immuncomprimised patients are in risk group for retrophayengeal abscess formation. Retropharyngeal lymph nodes counts more in children in comparison to adults thus it is more common in children. ${ }^{2,3}$ In this article we present three retropharyngeal abscess cases with life threatining risks.

\section{Cases}

\section{Case I}

50years old male patient referred to emergency department complaining from dysphagia and sore throat. In history it was learned that he has been living in a refugee camp. He had chronic hepatitis $\mathrm{C}$ infection and drug addiction. In physical examination; swelling occupying the pharyngeal cavity, fever 38.4 Celsius and dyspnea was noted. Poor oral hygiene was observed. A neck computer tomography imaging of the neck was planned and it was reported as retropharyngeal abscess (Figure 1). Respiratory arrest occurred while the patient was being transferred to emergency operating room for abscess drainage and a tracheotomy was performed. After tracheotomy abscess drainage was performed under general anesthesia in Trendelenburg position. He was observed in intensive care unit for two days after surgery and transferred to ear nose throat clinic. After 7 days follow up the retropharyngeal abscess was not recovered and a second intervention and abscess drainage was performed on seventh day. The patient was decannulated on postoperative first day and discharged with full recovery.

\section{Case 2}

A 52year old male patient with dysphagia, sore throat, hemoptysis, cough and neck swelling referred to emergency department. He had diabetes mellitus and underwent dental filling ten days before. Physical examination revealed a swelling on the anterior pharyngeal wall. In videolaryngoscopic examination a fistula orifice and purulent discharge on the right pyriform sinus was observed (Figure 2). Neck magnetic resonance imaging (MRI) planned with retropharyngeal abscess diagnosis (Figure 3). Due to spontaneous drainage surgical intervention was not considered.

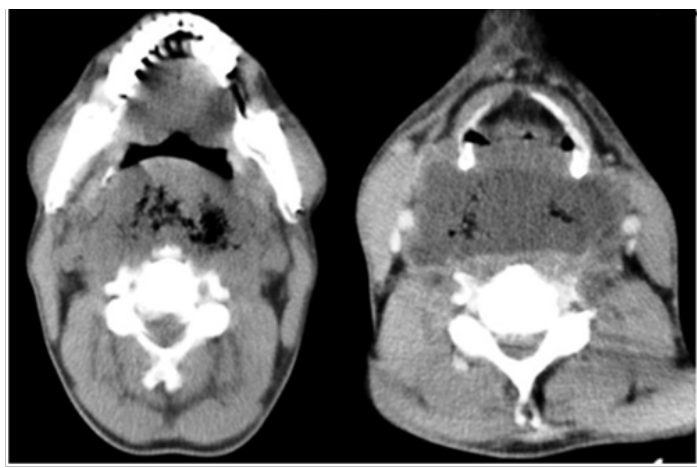

Figure I Neck CT;Airway obstruction and air traps in retropharynx.

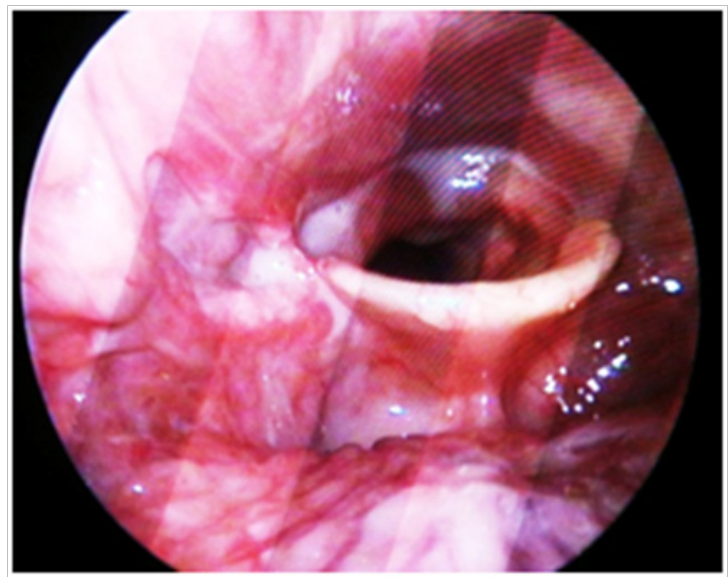

Figure 2 Drainage orifice on the right pyriform sinus, purulent drainage tot the larynx.

\section{Case 3}

16years old male patient with complaints of dyspnea, dysphagia, neck swellling and fever referred to emergency depatment. Exitance 
of Type 1 diabetes mellitus was noted from the the history. He had poor general condition and poor oral intake, and a neck MRI administrated. Neck MRI revealed a retropahryngeal abces. A surgical drainage was planned while a sudden spontan rupture developed resulting with severe dyspnea and hypoxia, and subcutaneous neck crepitation. The patiant was trasferrerd emergency operating room. Abces formation accompanied by muscle and facia atrophy observed in surgery (Figure 4). Daily wound care with secondary healing was performed resulting with complete recovery.

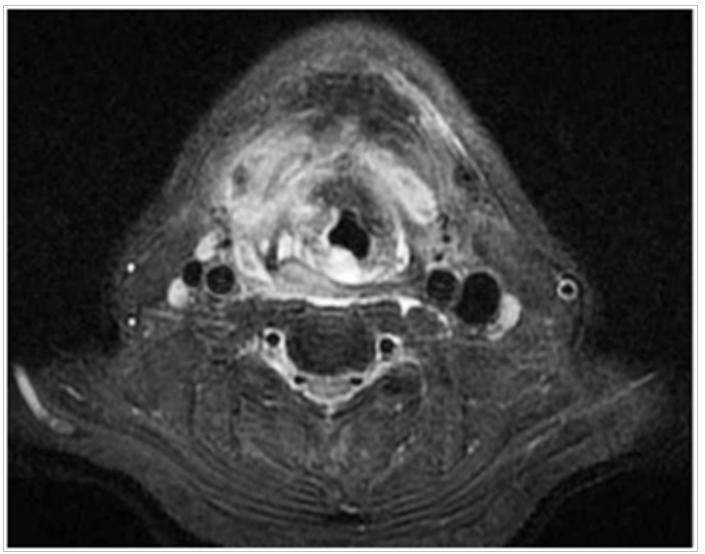

Figure 3 Neck MRI findings.

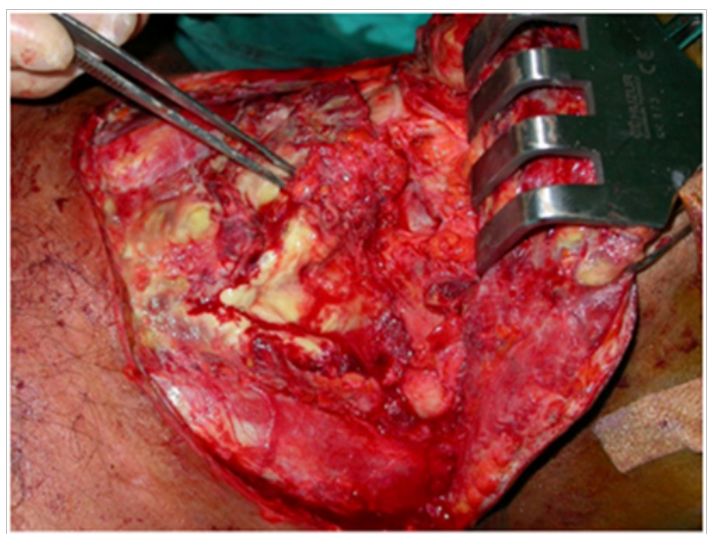

Figure 4 Common abscess origins in neck spaces with muscle and fascia necrosis.

\section{Discussion}

Retropharyngeal abscess may cause highly mortal complications such as; airway obstruction, aspiration pneumonia, epidural abscess, jugular venous thrombosis, sepsis and carotid artery erosion. ${ }^{4}$ The patients are male children in general with history of trauma, foreign body reaction and dental infections. The cases were male and two of their comorbid diseases were history of dental infections, diabetes mellitus, hepatitis $\mathrm{C}$, drug abuse and poor oral condition ${ }^{5}$ (Table 1).

Clinical presentation for retropharyngeal abscess is variable and nonspecific, thus the differential diagnosis may be difficult. Presence of diabetes mellitus can mask the symptoms. ${ }^{6}$ Sore throat, fever, odynophagia, dysphagia, dyspnea are main symptoms in adults. The two of the patients have complained from dyspnea, while the other patient had cough and sore throat. Pharyngeal edema, nuchal rigidity, cervical adenopathy are common physical examination findings. ${ }^{4}$ All of the patients had pharyngeal edema, swelling, nuchal rigidity, and cervical adenopathy. Two of them had stridor.
Table I Summary of Three Cases

\begin{tabular}{|c|c|c|c|c|}
\hline & Age & Sex & Etiology & Comorbidity \\
\hline Case I & 50 & Male & $\begin{array}{l}\text { Poor oral } \\
\text { hygenie, Drug } \\
\text { abuse }\end{array}$ & $\begin{array}{l}\text { Refugee Camp, HCV } \\
\text { Infection }\end{array}$ \\
\hline Case 2 & 52 & Male & Dental & Diabetes Mellitus \\
\hline Case 3 & 16 & Male & Dental & Diabetes Mellitus \\
\hline
\end{tabular}

Computer tomography is useful for diagnosis but cannot distinguish abscess and cellulitis formation. Thickening and air in retropharyngeal region in plain $\mathrm{x}$-ray radiogram on lateral position is specific for diagnosis. ${ }^{7}$ All of our patients underwent radiologic evaluation for certain diagnosis. Wide spectrum antibiotic administration may not be sufficient for control of the abscess and a combined surgical intervention is recommended. ${ }^{8}$ In these three cases we have administrated antibotherapy (ceftriaxone $1 \mathrm{gr}$ intravenous $2 \times 1$, metronidazole $500 \mathrm{mg}$ intravenous $2 \times 1$ ) in all of them but two patients underwent surgical drainage. Due to spontaneous drainage of the one case surgery was not performed. It is also vital to control comorbid diseases. Two of our patients had diabetes mellitus and diabetes was controlled via internal medicine consultation.

Although retropharyngeal abscess are rare in adults the results may be mortal thus it is an emergency condition. Surgical drainage is performed in Trendelenburg position in operating room. Control of comorbid conditions and oral intake and liquid and electrolyte levels should be well monitored for complete recovery.

\section{Summary}

Although retropharyngeal abscess is not common in adults; in case of poor social conditions and comorbid diseases, retropharyngeal abscess may also be seen in adults. Thus it is essential to control comorbidity as well as abscess drainage accompanied with ant biotherapy. Emergency intervention due to sudden airway obstruction should be kept in mind.

\section{Acknowledgements}

This paper has been presented in $34^{\text {th }}$ National Turkish Otolaryngology Head \& Neck Surgery Congress, October 2012, Antalya.

\section{Conflicts of interest}

Author declares there are no conflicts of interest.

\section{Funding}

None.

\section{References}

1. Goldenberg D, Golz A, Joachims Z. Retropharyngeal Abscess: a clinical review. J Laryngol Otol. 1997;111(6):546-550.

2. Arora S, Sharma JK, Pippal SK, et al. Retropharyngeal abscess following a gunshot injury. Braz J Otorhinolaryngol. 2009;75(6):909.

3. Marques PM, Spratley JE, Leal LM, et al. Parapharyngeal abscess in children: five year retrospective study. Braz J Otorhinolaryngol. 2009;75(6):826-830.

4. Herzon FS, Martin AD. Medical and surgical treatment of peritonsillar, retropharyngeal, and parapharyngeal abscesses. Curr Infect Dis Rep. 2006;8(3):196-202. 
5. Singh I, Meher R, Agarwal S, et al. Carotid artery erosion in a 4-year child. Int J Pediatr Otorhinolaryngol. 2003;67(9):995-998.

6. Sato K, Izumi T, Toshima $\mathrm{M}$, et al. Retropharyngeal abscess due to methicillin-resistant Staphylococcus aureus in a case of acute myeloid leukemia. Internal Med. 2005;44(4):346-349.
7. Chatrath $\mathrm{P}$, Black M, Blaney S. Subclinic presentation of massive retropharyngeal abscess. J R Soc Med. 2001;94(1):36-37.

8. Wang LF, Kuo WR, Tsai SM, et al. Characterizations of life-threatening deep cervical space infections: a review of one hundred ninety-six cases. Am J Otolaryngol. 2003; 24(2):111-117. 